\title{
SIMPÓSIO: CINCO QUESTÕES SOBRE OS ESTUDOS DE GÊNERO NA AMÉRICA LATINA
}

\author{
Symposium: five questions on gender studies in Latin America
}

Simposio: Cinco Preguntas sobre los estudios de Género en América Latina

ENTREVISTAS COM:

ANA PELUFFO

ANDREA ANDÚJAR ${ }^{I I}$

BILA SORJ ${ }^{I I I}$

BÁRBARA SUTTON ${ }^{I V}$

CATALINA TREBISACCEV

CECILIA MARIA BACELLAR SARDENBERGVI

DORA BARRANCOS VII

JOANA MARIA PEDROVIII

MARY GARCIA CASTROIX

NORA DOMÍNGUEZ

SUSANA ROSTAGNOL ${ }^{\mathrm{XI}}$

ENTREVISTAS CONCEDIDAS A ALEJANDRA JOSIOWICZ ${ }^{\mathrm{XI} *}$

DOI: http://dx.doi.org/10.1590/S2178-14942020000200002

University of California - Davis, Estados Unidos.

"Universidad de Buenos Aires - Buenos Aires, Argentina.

"'Universidade Federal do Rio de Janeiro - Rio de Janeiro (RJ), Brasil.

"University at Albany, State University of New York - Albany, Estados Unidos.

vUniversidad de Buenos Aires - Buenos Aires, Argentina.

vUniversidade Federal da Bahia - Salvador (BA), Brasil.

VIIUniversidad de Buenos Aires - Buenos Aires, Argentina.

"IIIUniversidade Federal de Santa Catarina - Florianópolis (SC), Brasil.

'x Universidade Federal da Bahia - Salvador (BA), Brasil.

XUniversidad de Buenos Aires - Buenos Aires, Argentina.

XUniversidad de la República - Montevidéu, Uruguai.

"

*Pesquisadora do Instituto Interdisciplinario de Estudios de Género, da Facultad de Filosofía y Letras, da Universidade de Buenos Aires (IIEGE-FFyL-UBA), do Consejo Nacional de Investigaciones Científicas y Técnicas (CONICET) e pósdoutoranda no Programa de Pós-graduação em História, Política e Bens Culturais (PPHPBC) da Escola de Ciências Sociais da Fundação Getúlio Vargas (CPDOC/FGV) (alejandra.josiowicz@fgv.br).

(D) https://orcid.org/0000-0002-3525-1833 


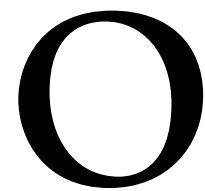

seguinte simpósio é uma entrevista coletiva feita a 11 figuras centrais dos estudos de gênero e do feminismo, professoras e pesquisadoras de diversas instituições do Brasil, da Argentina, do Uruguai e dos Estados Unidos, provindas dos âmbitos da sociologia, a crítica literária, a história e a antropologia, na qual elas refletem sobre o presente e o futuro do campo. Elas não só foram pioneiras da constituição da área e centrais na sua legitimação enquanto campo disciplinar, mas também são hoje vozes protagonistas e inovadoras tanto no que diz respeito à produção de conhecimento quanto à intervenção e conscientização política, em diversas esferas da vida social e diante de diferentes públicos. Na entrevista, é possivel perceber a interrelação constante e altamente produtiva entre conhecimento acadêmico e lutas políticas, de acordo com as particularidades de cada área de conhecimento e espaço institucional e geopolítico. Também é importante apontar a alta dinamicidade da relação entre o campo dos estudos de gênero e as diferentes disciplinas de conhecimento, que não só gerou uma verdadeira revolução em vários campos, mas também levou à incorporação de novas ferramentas teórico-críticas e ao diálogo com outros movimentos sociais. Em conclusão, são autoras, mulheres intelectuais, acadêmicas e militantes que estabelecem conexões entre a escrita, a produção acadêmica, e o corpo, o desejo e o sofrimento, próprio e das outras, enquanto modos e possibilidades de escuta, conhecimento e comunicação.

1. ¿Cómo ves el actual estado del campo de los estudios de género en América Latina? ¿Qué temas, problemas y autores destacarías? / Como você vê o atual estado do campo dos estudos de gênero na América Latina? Que temas, problemas e autores você destacaria?

Ana Peluffo: Creo que es un momento de mucha efervescencia política en el que se están estableciendo productivos cruces entre la academia y el activismo callejero. Al mismo tiempo, la radicalización y transnacionalización del feminismo y el transfeminismo han suscitado respuestas brutales en contra de todas sus propuestas. Un ejemplo de esto sería lo que están tratando de hacer los republicanos con los derechos reproductivos de las mujeres en los Estados Unidos, un país en el que el propio presidente defendió su derecho de usar y sexualizar los cuerpos femeninos en su famosa frase "grab them by the pussy". Pese a eso, recibió el voto de $53 \%$ de las mujeres blancas que lo votaron por sus propuestas racistas en contra de los negrxs y los latinxs. Otro ejemplo de esta polarización y reacción en contra del feminismo serían los ataques a las feminazis en Argentina que exacerban el estereotipo de la feminista resentida o amargada, y la campaña electoral antiabortista de Juan José Gómez Centurión en las elecciones pasadas del mismo país, un político al que algunos memes representaron en su momento como una tortuga masticando un pañuelo verde. En Brasil, el gobierno de Bolso- 
naro ve las ideologías de género como una amenaza al patriarcado. Cuando Judith Butler fue de visita, circularon videos en los que la gente la atacaba furiosamente en el aeropuerto por destruir el orden familiar heteronormativo. Incluso las masculinidades se volvieron un campo semiótico de lucha para Bolsonaro cuando su hijo circuló virtualmente una foto en la que aparecía rodeado de fusiles al lado del hijo de Alberto Fernández vestido de mujer. El mensaje subliminal de esa campaña era celebrar que el gobierno de Bolsonaro se apoyaba en una idea de la masculinidad hiper-viril por oposición a las masculinidades queer, trans o fluidas que reivindica el feminismo. Tanto en el caso de Bolsonaro como en el de Trump, el antifeminismo explícito y su odio a los grupos LGBTIQ se articula con ataques al planeta, al ecosistema y a las poblaciones indígenas vulneradas por el capitalismo.

Andrea Andújar: En las últimas décadas, el campo de los estudios de género creció sensiblemente, ofreciendo claves analíticas, teóricas y metodológicas sumamente potentes para profundizar nuestra comprensión de la historia de las sociedades latinoamericanas. La expansión de este campo nos brindó también novedosas miradas y herramientas para intervenir políticamente en nuestras sociedades, iluminando y nominando opresiones de diverso tipo, donde las originadas en la interacción entre patriarcado y capitalismo ocupan un lugar preponderante. En ese sentido, el desarrollo de los estudios de género está intrínsecamente vinculado con las demandas políticas de los movimientos feministas, de mujeres y de las sexualidades disidentes, en una interpelación que genera enriquecimiento mutuo en términos de saberes, preguntas e instrumentos de conocimiento y de acción colectiva en pos de cambiar esta sociedad. En cuanto a temas y problemas destacables, reduciré el listado a aquellos ligados con mis intereses como historiadora especialista en la historia social del trabajo. Entre ellos, menciono entonces los vinculados con el estudio de los mundos del trabajo: la problematización del concepto de trabajo, de la noción de clase y de las tensiones dentro de la propia clase trabajadora a la luz de los cruces entre clase y género; la manera en que el género modula la identidad, la cultura y los andariveles del conflicto de clases; las pautas de sexuación de las políticas de estado y de las demandas por derechos. Respecto de las autoras - también vinculadas a este subcampo de la historia - destaco a Dora Barrancos, Mirta Lobato, Joana María Pedro, Margareth Rago, Sandra McGee Deutsch, Temma Kaplan, Heidi Tinsman y Lara Putnam.

Bila Sorj: Tivemos no Brasil, e em muitos países da América Latina, um forte desenvolvimento e institucionalização dos estudos de gênero desde os 1980. Sobretudo a partir dos anos 2000, em função da expansão do ensino superior no país, os cursos e núcleos de pesquisa sobre gênero se expandiram por várias regiões do país. Antes concentrados no Sul e Sudeste, hoje estão presentes em todas as regiões do país. Além disso, os estudos de gênero 
passaram a incorporar a temática da sexualidade, diversificando suas pautas de pesquisa. 0 que mais chama a atenção é que os estudos de gênero e sexualidade passaram a envolver, cada vez mais, audiências não acadêmicas formadas por públicos diversos como organizações não governamentais, movimentos sociais, o Estado, professores de ensino fundamental e médio. Além disso, a questão das desigualdades de gênero passou a estar muito mais disseminada no discurso público. Todavia, a ascensão de um governo de extrema-direita no Brasil em 2019 representa um grande desafio para essa área de estudos. 0 Brasil é o primeiro país do mundo em que um presidente declara que o principal objetivo do seu governo é combater a chamada ideologia de gênero.

Bárbara Sutton: El campo de estudios de género en América Latina es un área con gran potencial de crecimiento, y de suma relevancia para interpretar los temas sociales de actualidad, su raigambre histórica y las demandas de los movimientos de mujeres, feministas, LGBTQ y por la justicia social. Estos estudios son importantes también para la intervención en el diseño de políticas públicas a nivel local e internacional. Es un campo que continúa generando conocimientos emancipatorios, y que ha inspirado y brindado herramientas teóricas y prácticas a un sinnúmero de personas interesadas en cambiar la realidad. Estos estudios tienen la capacidad de iluminar temáticas políticas y sociales candentes, como por ejemplo, la lucha por el derecho al aborto, la violencia de género o las controversias en torno al lenguaje inclusivo, entre otras temáticas asociadas con el campo. Pero esta mirada también es importante en relación a cuestiones que quizá no parecen obviamente "de género", pero cuyo abordaje puede ser enriquecido por un análisis en clave de género, como ser los movimientos de derecha y sus liderazgos políticos; la destrucción ambiental, el cambio climático y el extractivismo; el militarismo y los procesos de paz; el impacto de las políticas económicas neoliberales; temas de memoria colectiva y justicia transicional y la persistencia de la lógica colonial en las relaciones y sistemas dominantes.

Catalina Trebisacce: Los estudios de género dan muestras de una consolidación en los centros académicos de nuestra región. Han aumentado considerablemente las investigaciones en este campo y lxs investigadorxs que desarrollan allí enteramente su carrera. Desde los años 90 a esta parte han proliferados los equipos de trabajo, los eventos académicos, las instancias de formación de grado y postgrado en estas temáticas. Ahora bien, no podemos dejar de observar que en algunos países el contexto político resulta, sin embargo, amenazante. Como es el caso de Brasil, que es un país que se destaca por la producción en este campo, pero que debe combatir con actores políticos reaccionarios como Escuela Sin Partido, Ixs políticxs evangelistas y el mismo presidente Bolsonaro. Los temas o problemas centrales están definidos por las realidades diferenciales que tiene la región en cada uno de sus contextos locales. Para vol- 
ver al caso de Brasil, encuentro que en este momento las investigaciones están especialmente volcadas al estudio y a la compresión de la organización de las fuerzas conservadoras, por ejemplo. Pero, en líneas generales, podríamos destacar la importancia de las investigaciones que recuperan la historia de los movimientos feministas y LGTBIQ+ locales, los estudios orientados a repensar nuevos contratos sexuales, los que investigan masculinidades, activismo medioambiental y dinámicas migratorias en la región desde una perspectiva de género.

Cecília Maria Bacellar Sardenberg: No Brasil, como na América Latina como um todo, vivenciamos um momento sui generis: por um lado, constatamos um grande crescimento dos estudos de gênero feministas, com novas abordagens originais, latino-americanas, nascidas da crítica decolonial, e com a criação de cursos de pós-graduação, mestrados e doutorados específicos. Por outro lado, vivemos um momento crítico de ataque por parte dos fundamentalismos religiosos (ou mesmo neofascistas) ao que denominam de ideologia de gênero, que ameaçam, inclusive, pessoas que trabalham no nosso campo de estudos. Acredito que o fazer feminista nas ciências e na academia não só é possível como se faz necessário, seja como crítica ao androcentrismo nas ciências, seja no tocante à desconstrução das práticas e estruturas patriarcais acadêmicas, ou mesmo na sociedade como um todo. Creio ser equivocado pensar esse campo como algo contrário ao ativismo político, uma vez que ele abre espaço para a reprodução e transformação dos feminismos, para a formação de novas gerações de feministas. Não se há de negar que há tensões entre os estudos e o ativismo feminista no Brasil (ou na América Latina como um todo), mas as conexões ainda se sobrepõem. Ou seja, o feminismo acadêmico no Brasil, em seu conjunto, permanece como um importante "braço" do ativismo feminista, constituindo-se, ainda hoje, como um dos principais espaços de crescimento do movimento e de formação de novas e novos agentes feministas no país. De fato, tenho mais de 45 anos de vida acadêmica e posso afirmar, com toda convicção, que fazer feminismo acadêmico no Brasil implica lutas constantes para garantir a legitimidade e espaço para o desenvolvimento de nossos cursos, estudos, pesquisas e atividades de extensão universitária (Costa; Sardenberg, 1994; Sardenberg, 1998). Por certo, isso vem se tornando ainda mais difícil desde o golpe de 2016 contra o Governo Dilma e, mais intensamente, desde janeiro do ano passado (2019), com a chegada ao poder de um governo retrógado, antifeminista, anticientífico, em guerra com as universidades e com o que definem como ideologia de gênero. Por isso mesmo, temos um papel fundamental na luta contra o Estado que ora se volta contra os feminismos e, em especial, contra os estudos de gênero, incentivando uma onda de backlash contra nossas conquistas, contra nosso trabalho ou mesmo contra a nossa existência.

Dora Barrancos: Es un momento de vorágine por la implantación que han conseguido en toda la región. Es difícil señalar para cada país los temas dominantes y realizar una escala de orientaciones, aunque han ganado enorme lugar los análisis de la diversidad sexo social. 
Basta señalar lo que ocurre en la Argentina — si bien debe reconocerse el salto cuántico particularmente realizado por la academia en nuestro país, uno de los de mayor producción en los últimos años. En el CONICET hace unos dos años, había casi doscientos proyectos de investigación focalizados en la condición femenina, las relaciones de género, las masculinidades y la diversidad sexo social. La enorme mayoría correspondía a trabajos doctorales o posdoctorales y esto da una idea de la enorme renovación habida.

Joana Maria Pedro: Vejo a discussão de gênero na América Latina sob ataque. A ideia de que se estaria divulgando uma ideologia de gênero, já bem discutida pela academia, tem sido instrumento para ganhar eleições e atender a uma pauta moral e reacionária. Já foram registrados vários casos de professores processados por falar de gênero e sexualidade em sala de aula. O MEC — Ministério da Educação no Brasil — tem ameaçado excluir, dos livros didáticos, qualquer referência a gênero, sexualidade e feminismo. Por outro lado, mais do que nunca, as pessoas estão curiosas com esta discussão. Nos cursos que são realizados, há uma busca muito grande pelo tema. No Seminário Internacional Fazendo Gênero 12, que ocorrerá entre 26 e 31 de julho, em Florianópolis, Santa Catarina, mais de 6.500 pessoas inscreveram-se na forma de apresentação de comunicação oral, coordenação de simpósios, ministrantes e ouvintes de minicursos e divulgação de pôster. Isso demonstra que todas essas "proibições" e tentativas de desqualificar a discussão estão dando mais divulgação às questões de gênero e trazendo mais pessoas interessadas à temática. Acompanho isso no Brasil, mas não posso dizer que isto esteja ocorrendo em outros países. No documentário Género bajo ataque https://www.youtube.com/watch?v=Aj3St_zUM7M, de 2018, observa-se que no Peru, Costa Rica, Colômbia e Brasil, a chamada ideologia de gênero tem sido usada para ganhar espaços políticos e eleições nacionais: utilizam o fundamentalismo cristão para atuação política. No Brasil, a partir de 2010, são as escritoras negras que estão trazendo discussões sobre interseccionalidade e as questões decoloniais que têm ganhado espaço. Grande parte delas estendeu às redes sociais suas reflexões, outras partiram das redes sociais para a publicação de trabalhos em forma de livros. 0 feminismo negro tem atuado nos movimentos sociais e, também, levado questionamentos para o feminismo acadêmico. Esse é o caso de autoras como Djamila Ribeiro, nos livros 0 que é lugar de fala? (2017) e Quem tem medo do feminismo negro? (2018). Algumas autoras estão falando de quarta onda feminista. Esse é o caso de Heloisa Buarque de Hollanda (2018) e Marlise Matos (2010). Em outros países da América Latina, não tenho condições de destacar com muito conhecimento; posso, apenas, dizer quem eu conheço. Na Argentina: Alejandra Oberti, Dora Barrancos, Alejandra Ciriza, Andrea Andújar, Agustina Cepeda, Adriana María Valobra, Maria Luiza Femenias, Elizabeth Jelin, Nora Domínguez, María Inés Rodríguez. No Chile: Margarita Iglesias, Olga Grau Duhart, 
Asunción Lavrin, Teresa Valdés, Eliana Largo, Sonia Montecino Aguirre, Nelly Richards, Claudia Darrigrandi Navarro, Rachel Olea. No Paraguai: Line Bareiro, Clyde Soto, Mary Monte, Nadimy Perla Yore, Carmen Colazo, Olga Caballero Aquino, Barbara Potthast, Carmen Echauri. Na Bolívia: Lourdes Monteiro, Gloria Rubin e Teresita Silvero. No Uruguai: Graciela Sapriza.

Mary Garcia Castro: 0 campo de estudos de gênero na América Latina é heterogêneo e em diálogo com os avanços em ciências sociais, arte e literatura. 0 que mais me entusiasma é um feminismo preocupado com o problema maior destes tempos, a barbárie do mundo capitalista e, como bem colocam autores do debate sobre decolonialidade, com a colonização do poder, do saber e do ser. Ora tal leque de interesses não nasce só de biografia ou vontades, é estimulado também por desafios que o campo vem apresentando, o novo, que me atraíram para a compreensão destes tempos. De fato, são temas destes tempos que questionam a codificação do feminismo como conhecimento identitário, sua herança iluminista e afirmam que cada vez mais o feminismo, especialmente correntes na América Latina e África, se preocupam com mudar o mundo, combater desigualdades socio-sex-raciais e por uma perspectiva interdisciplinar com atenção ao papel transgressor das artes. 0 feminismo decolonial, o ecofeminismo, o feminismo negro, os estudos queer, os estudos sobre cuidados e as mobilizações de jovens críticos ao status quo são marcas contemporâneas de um feminismo atento a propostas macro e micro que vão além da inclusão das mulheres na ordem social em curso. As/os autoras/es a que mais recorro em trabalhos com aquelas preocupações são: Aníbal Quijano, Yuderkys Espinosa Miñoso, Rita Segato, Maria Lugones, Lélia Gonzalez, Beatriz Nascimento, Suely Carneiro, Heleieth Saffioti, Silvia Federici, Heloisa Buarque de Hollanda, Kabengele Munanga, Manuela Carneiro da Cunha, Pierre Bourdieu, Élisabeth Badinter, Nancy Chodorow, Carole Pateman, Donna Haraway, Teresa de Lauretis, Ana Miranda, Conceição Evaristo, Oyeronke Oyewumi e Ifi Amadiume.

Nora Domínguez: Caeré en el lugar común de hablar de la expansión del tema, del estallido de los cuerpos en las calles, de la confección de libros en un abanico enorme de disciplinas, de la evidente elaboración teórica que articula cuerpo y pensamiento, del empuje de leyes y políticas públicas (esto de acuerdo a las opciones políticas de cada país). Los estudios de género, es decir, el brazo académico de este estallido es igualmente productivo, profuso, imparable en temas y problematizaciones.

Susana Rostagnol: En muchas universidades, existen centros de estudios de género desde hace varias décadas. Esto debería hablarnos de cierta madurez del campo en la región. Mas allá de ello, quiero subrayar que para mí existe una diferencia en estudios de género y estudios feministas. El énfasis de las teorías feministas difiere en los distintos estudios de género. Creo que cada vez más los estudios de género son estudios feministas. Mi respuesta 
estará condicionada por mi disciplina de origen (antropología) y por mis líneas de investigación (género, cuerpo y sexualidad). Es a través de esos cristales que deben leerse los temas, problemas o autores a destacar. Un tema-problema que ha concitado interés es el abordaje interseccional, es decir, problematizar la categoría género y estudiarla en su intersección con otros ejes de dominación, especialmente raza, clase e identidad sexual. Una de las autoras que destaco en esta línea es la antropóloga colombiana Mara Viveros Vigoya. Los estudios sobre las sexualidades desde la perspectiva feminista también han tenido cierto desarrollo en articulación con otras vertientes (como la teoría queer) para abordar estas temáticas. Otro núcleo de tema-problemas radica en los derechos reproductivos (especialmente en relación al aborto) y a la ciudadanía sexual y a la condición de la mujer en general, en relación a la creciente ola conservadora. Algunos autores en esta línea son Leticia Sabsay. Temáticas relativas a la decolonialidad - y en ese sentido también ligado al estudio del propio movimiento feminista y a sus diversidades - han concitado interés. Puede nombrarse a Rita Segato y Aida Hernández. La violencia contra las mujeres es otro tema. Aquí destaco aportes de Julia Monárrez; Miriam Jimeno, Montserrat Sagot y la ya mencionada Rita Segato.

2. ¿Cómo ves la relación entre los estudios de género y las diferentes áreas del conocimiento? ¿Cuál ha sido la contribución de los estudios de género a las diferentes disciplinas y campos de investigación? / Como você vê a relação entre os estudos de gênero e as diferentes áreas de conhecimento? Qual é a contribuição feita pelos estudos de gênero às diferentes disciplinas e áreas de pesquisa?

Ana Peluffo: Un área de intersección disciplinaria que ha surgido dentro de los estudios de género es el llamado "giro afectivo" que visibiliza la ideologización de los afectos y las emociones. Durante mucho tiempo se excluyó a las mujeres del campo de la racionalidad junto con distintos grupos racialmente otros. Me parece que es imperativo desnaturalizar y desencializar las emociones. Tal y como lo teorizo en mi último libro, En clave emocional (2016) las emociones se van sexualizando a lo largo del tiempo y provocan asimetrías y desigualdades entre los cuerpos. En este sentido, el trabajo del feminismo en sus distintas modalidades consiste en mostrar que la utopía amorosa tal y como la conocemos no se puede separar de la relación entre heternormatividad forzada, patriarcado y capitalismo. En el siglo XIX, el sufrimiento amoroso estaba intrínsecamente asociado a los celos, como lo demuestra Eva Illouz en uno de sus libros más recientes. Esa visión del amor basada en la dueñidad sigue circulando a nivel residual en un mercado sexual que piensa los cuerpos de las mujeres como objetos de tráfico. A grandes rasgos, la violencia de género y la alta tasa de femicidios latinoamericanos se relacionan con esta idea hegemónica del amor como posesión. Al mismo 
tiempo, hay emociones tradicionalmente pensadas como masculinas que bien gestionadas son útiles para la política y pueden desembocar en cambios sociales importantes. Un ejemplo de esto sería la performance del colectivo chileno LASTESIS que se volvió viral recientemente y en la que se gestiona la rabia de manera sónica, performática y colectiva.

Andrea Andújar: La relación entre los estudios de género y las demás áreas científicas es mucho más fluida que hace una década atrás, cuando demostrar la importancia de este campo para el conocimiento científico nos exigía mayores esfuerzos y batallas en diversos foros de intercambios con colegas y con estudiantes. Ciertamente aún hay disciplinas más refractarias a los estudios de género. Incluso, en aquellas que son más receptivas, como las humanísticas y sociales, perviven mojones de resistencia o simplemente, de aceptaciones pasivas, dispuestas a concederle cierto valor al campo, pero no a integrarlo a la reflexión sobre el pasado o el presente y menos aún, a la investigación. Igualmente, es destacable la amplia difusión ganada por los estudios de género, así como la solvencia en que se amparan. Ello ha sido el resultado no solo de la perseverancia de sus precursoras y su voluntad y capacidad de interesar a nuevas generaciones de investigadorxs para el desarrollo del campo. También fue el fruto del logro generado por las investigaciones en su contribución a conocer más y mejor el mundo que nos rodea en términos de su historia y de las formas y mecanismos que generan y reproducen la desigualdad y la opresión. Y ese conocimiento contribuye, a su vez, a buscar cómo cambiar ese mundo. En el campo de la historia social del trabajo con perspectiva de género en la Argentina, área en que inscribo mis investigaciones, las contribuciones del desarrollo de los estudios de género son variadas. Entre ellas se cuenta la problematización y enriquecimiento del concepto de clase denotando que las clases sociales son formadas por sujetos sexuados; el dislocamiento de los límites entre la esfera doméstica y la esfera pública, haciendo de una y otra objetos de estudio de la historia, y evidenciando la centralidad de las actividades del cuidado para la reproducción del sistema capitalista. Denoto la importancia de la sexualidad, el mundo de los afectos y de las emociones en la vida de la clase trabajadora, inquiriendo por las relaciones de sociabilidad y la vida cotidiana de la clase trabajadora fuera de los espacios productivos extra-domésticos.

Bila Sorj: Desde o ângulo da sociologia, é possível afirmar que os estudos de gênero operaram uma verdadeira revolução conceitual. Todos os temas caros à disciplina foram repensados, como trabalho, família, violência, política e outros, desafiando as categorias de análise fundamentais então em voga. Na sociologia do trabalho, as abordagens de gênero confrontaram as concepções prevalecentes de trabalho, centradas no trabalho mercantil, ao ampliar o seu escopo e incluir o trabalho doméstico não remunerado; na sociologia da família, introduziu-se o conceito de poder que desafiava as visões da complementariedade de papeis 
sociais masculinos e femininos; nos estudos de violência, criaram-se novos conceitos, como o de violência de gênero/doméstica, que, mais do que as características individuais dos seus agentes, refletem as desigualdades de poder entre homens e mulheres; na política, um dos pilares da democracia moderna, a separação entre a esfera pública e privada, longe de ser uma dualidade neutra, passou a ser vista como uma separação hierarquizada entre homens e mulheres, o masculino e o feminino.

Bárbara Sutton: Los estudios de género han tenido un efecto transformador en la academia, no sólo en términos de la proliferación de programas de grado y de posgrado identificados con el campo, sino en la manera en que ha alentado a varias disciplinas a tomar en cuenta discusiones epistemológicas, pedagógicas y metodológicas que se han dado dentro del feminismo y los estudios queer. Algunas herramientas teóricas y analíticas relevantes para los estudios de género han sido incorporadas en distintitas disciplinas y campos de investigación. Este es el caso, por ejemplo, de la noción de interseccionalidad, que emerge de las luchas y teorizaciones de los feminismos de color, y que alienta a entender la desigualdad de género de manera imbricada con otras desigualdades, incluyendo aquellas basadas en la raza, clase, sexualidad, nación y otras jerarquías sociales. Este aporte reviste importancia para campos como la sociología, que se interesa por las relaciones de poder y los sistemas de desigualdad. Las temáticas de género, así como también la necesidad de entender la vida y la historia de las mujeres desde una posición no androcéntrica, han impactado el foco de investigaciones y conocimiento académico en varias disciplinas. En Estados Unidos (donde estoy basada) la sección sobre "Sexo y Género" ha sido la unidad temática más grande del American Sociological Association (Asociación Americana de Sociología) en el 2019 y otros años.

Catalina Trebisacce: Los estudios de género pasaron de transitar la academia de un modo relativamente encapsulado, es decir aislados de otros campos, a convertirse en una perspectiva que tiende a atravesar todas las investigaciones de calidad. En las diferentes áreas de trabajo, la perspectiva que introducen los estudios de género resulta estimulante, pues discute desde los sujetos que han sido protagonistas de los análisis científicos hasta las herramientas teóricas construidas para dichos análisis. Poco a poco, las distintas disciplinas van cayendo en la cuenta de la profunda revolución analítica que traen los estudios de género.

Cecília Maria Bacellar Sardenberg: Os estudos feministas vêm se constituindo como um dos campos de estudo caracteristicamente multi, pluri, inter e transdisciplinar por excelência, contribuindo para a crítica ao androcentrismo presente nas diferentes áreas de conhecimento. Essa crítica avançou a partir da construção do conceito de gênero, vez que ele pode operar como um instrumento de análise do impacto das ideologias na estruturação, não apenas do mundo social, mas também do intelectual. Ela tem assim revelado que, para além 
da exclusão das mulheres do mundo da ciência, o androcentrismo tem um papel determinante não só na construção da cultura da ciência, mas também no próprio conteúdo dos conhecimentos produzidos.

Dora Barrancos: Sin duda las disciplinas más conmovidas son las correspondientes a las Ciencias Sociales y Humanas, aunque la participación cuantitativa es disímil. En el análisis de las investigaciones hospedadas en el CONICET al que hice referencia, las proporciones mayores de tópicos de género concernían a historia, sociología, antropología y, en menor cuantía, aparecían las restantes. Destaco el enorme desarrollo habido en el campo de la historia, hay un crecimiento exponencial en el número de oficiantes.

Joana Maria Pedro: Tenho tido a sorte de trabalhar num doutorado interdisciplinar em Ciências Humanas na UFSC e isso tem me levado a participar de debates, bancas de tese e aulas nas quais a interdisciplinaridade está presente. Assim, além da contribuição evidente da categoria gênero para a História, e se a disciplina pretende narrar a trajetória humana, tem que levar em conta que este "humano" tem gênero. Infelizmente, ainda, algumas historiadoras/res não têm se aventurado em incluir essa categoria em suas pesquisas. Aventuram-se, em, no máximo, incluir mulheres em sua pesquisa. Raramente observam que, ao falar de homens, também estão focalizando gênero, ou seja, não olham a masculinidade dos homens, sobre os quais escrevem história. Mas sinto que, lentamente, isso está mudando. $\mathrm{Na}$ antropologia, esta discussão está bem mais avançada; tenho participado de bancas nas quais a discussão do campo não tem permitido esquecer o gênero. Minha surpresa tem sido a arquitetura (incluindo gênero), notando que as construções têm viés de gênero; e mais: as pessoas que discutem a cidade e políticas urbanas (um viés da arquitetura) têm incluído esta questão nos deslocamentos urbanos, por exemplo. Outra disciplina que tem incluído muito a questão de gênero é o Direito. Tenho participado de debates nos quais pesquisadoras/es têm sido muito demandados por direitos das mulheres e das sexualidades dissidentes. Esse é um campo no qual a questão de gênero tem crescido muito. Não posso me esquecer da área da saúde: Medicina, Farmácia, Educação Física, enfim, diferentes vertentes, têm incluído o gênero, pois a saúde tem gênero.

Mary Garcia Castro: Além de legitimar as relações sexuais engendradas como básicas para quaisquer área de conhecimento, ou como diriam [Carole] Paterman e Saffioti, como conhecimento que desvenda um contrato sexual subjacente ao contrato social, ou como diria Silvia Federici, a importância do trabalho da mulher para a reprodução social ampliada, o feminismo em muito contribui para a virada linguística, chamando atenção para a importância da sexualidade, do desejo, da subjetividade, das margens, dos estudos étnico antropológicos, da transgressão, dos estudos qualitativos e das representações sociais. Algumas das áreas mais afetadas por 
conhecimentos feministas ${ }^{1}$ têm sido a sociologia e a filosofia, já que desestabiliza parâmetros desses conhecimentos, como: o valor "leis gerais"; o princípio de objetividade; a limitação a sujeitos clássicos de mudanças sociais, como o operário na luta de classes. Aliás, questionando, como bem coloca o marxista [Domenico] Losurdo, que são tempos de discutir lutaS de classes e frentes como o patriarcado, sexualidades, desejo, raça e ecologia para o debate estrutural do e contra o capitalismo. Além de questionar a aposta quer de setores à direita como à esquerda em modelos desenvolvimentistas. Correntes feministas colaboram para o que [Edgar] Morin chama de "pensamento complexo", que vai além de amarras disciplinares e resgata saberes em uso e do campo das artes - campo que mais vem avançando no projeto de transgressão, contra colonialidade do saber (tema mais desenvolvido em Hollanda, 2020).

Nora Domínguez: En la Argentina, es difícil destacar un único campo. Me parece que las diferentes renovaciones y contribuciones se están dando en las áreas de la sociología, filosofía, teoría política, economía, pero también en los estudios sobre cine, arte, teatro. En el área de literatura, además, la perspectiva se amplió hacia el estudio de las diferentes subáreas. Se advierte un interés del tema en las áreas de lingüística por la incorporación del debate del lenguaje inclusivo. La lingüística fue un área poco permeable en los años y décadas anteriores. Creo que el uso de la perspectiva desde hace una década está mucho más aceptado en los niveles de grado que fueron más lentos en su recepción y actualmente son muy bien aceptados por los-as estudiantes que demandan activamente estos temas. Advierto también que es un momento donde se echa revista o se reconoce el trabajo hecho y se lo compendia o estudia como registro histórico de las maneras de pensar sus operaciones críticas. Es tiempo de archivos, de antologías críticas y literarias y de historias de la literatura desde esta perspectiva.

Susana Rostagnol: En el caso de la antropología, los estudios de género han tenido influencia en algunas áreas pero, sobre todo, ha impregnado la forma de abordar cualquier temática; en especial podríamos mencionar los campos de investigaciones sobre sexualidad, salud, cuerpo, religión, migraciones, trabajo, políticas públicas, pobreza, estudios urbanos, y podríamos continuar la lista. Es decir que, más que la incidencia en un área de estudio, ha impregnado buena parte de la mirada. Al mismo tiempo, ha promovido cuestionamientos metodológicos y epistemológicos interesantes, que hacen al quehacer investigativo.

\section{3. ¿Qué libros o artículos del área recomendarías o destacarías? / Quais livros ou} artigos da área você destacaria?

Ana Peluffo: Cualquier conversación sobre el feminismo debe subrayar la heterogeneidad de un campo múltiple en el que conviven feminismos blancos, fronterizos, trans, de color y latinxs. Al mismo tiempo, creo que es importante acabar con el colonialismo interno 
de la crítica que ve los feminismos anglosajones o europeos como teóricamente superiores, o más sofisticados, que los latinoamericanos. Esto se ve en el trabajo de citación que hacen los investigadores o estudiantes que jerarquizan, sin darse cuenta, los feminismos latinoamericanos y anglosajones. Aquí es importante poner a dialogar en igualdad de condiciones los feminismos de Butler, Braidotti, o Silvia Federici, para citar ejemplos no regionales, con los feminismos fronterizos, anticapitalistas, no hegemónicos o negros de Rita Segato, Sayak Valencia, Verónica Gago, bell hooks, Chela Sandoval o Gloria Anzaldúa, entre otras. También sería importante incorporar a la discusión todos los manifiestos del colectivo Ni una menos tal y como se recogen en varias antologías. En el campo de la crítica cultural, quisiera destacar el trabajo de una generación de críticas feministas muy combativa que produjo su obra en un clima intelectual hostil y adverso en los años 80 y que nos enseñó a pensar la cultura latinoamericana desde una óptica feminista. Me refiero a Sylvia Molloy que fue mi directora de tesis y a quien le debo mi interés por el género y la cultura de los afectos. Y también a Mary Louise Pratt con su idea muy citada de la "zona de contacto", a Josefina Ludmer con textos como "Las tretas del débil" o El cuerpo del delito y/o a Jean Franco que también estuvo a la vanguardia en su momento a la hora de pensar en clave de género la cultura mexicana. Como yo trabajo siglo XIX, me parece importante historizar los feminismos y trazar la genealogía de algunos de sus más importantes debates. En realidad, nos podríamos remontar a la carta de Sor Juana Inés de la Cruz y a su conocido poema "Hombres necios que acusáis" en el que ya Sor Juana denunciaba la doble moral del patriarcado. Aunque ahí no había un concepto de sororidad o red tal y, como lo conocemos hoy en día, Sor Juana construye una genealogía compensatoria de mujeres ilustradas que le permite hacer menos anómala su posición. Incluyo también el feminismo marxista de Flora Tristán que ha sido borrado de la historia y que de alguna manera abre la puerta, en términos afectivos, a los sufragismos de fin de siglo. Por otro lado, en el siglo XIX, hubo un debate transnacional muy rico desde espacios privados resemantizados como las veladas o tertulias de Juana Manuela Gorriti o de Clorinda Matto de Turner, donde se conversaba en modalidad causserie sobre la necesidad de que las mujeres pudieran acceder al campo del saber, del trabajo y de la política (un ámbito que aún hoy sigue siendo masculino).

Andrea Andújar: Mencionaré, primero, algunos trabajos que, si bien no refieren a América Latina, son cardinales para el estudio del pasado en clave generizada. Me refiero a El regreso de Martín Guerre y Mujeres en los márgenes: tres vidas del siglo XVII, dos libros de Natalie Zemon Davis (2004; 2013); los artículos de Catherine Hall (2013) "La historia de Samuel y Jemima: Género y Cultura de la clase trabajadora en la Inglaterra del Siglo XIX" y de Dorothy Thompson (2013) "Las mujeres y la radicalidad política en el siglo XIX: una dimensión 
ignorada". En cuanto a investigaciones locales sobre nuestra región en clave histórica, destaco "La puñalada de Amelia (o cómo se extinguió la discriminación de las mujeres casadas del servicio telefónico en la Argentina)" de Dora Barrancos (2008); La vida en las fábricas: trabajo, protesta y política en una comunidad obrera (1904-1970) de Mirta Lobato (2001); el artículo de Ann Farnsworth-Alvear (1996) "El misterioso caso de los hombres desaparecidos: género y clase en el Medellín de comienzos de la era industrial"; el artículo de Silvana Palermo (2007) " ¿Trabajo masculino y protesta femenina? La participación de las mujeres en la gran huelga ferroviaria de 1917"; el de Cristiana Schettini (2010), "Viajando solas: prácticas de vigilancia policial y experiencias de prostitución en América del Sur"; el de Laura Caruso (2016) "Hombres a bordo: experiencia laboral y masculinidades en el mundo del trabajo marítimo en la primera posguerra"; de Alejandra Vassallo (2007) "Sin Dios y sin jefe. Políticas de género en la revolución social a fines del Siglo XIX" y de Gabriela Mitidieri y Valeria Pita (2019) "Trabajadoras, artesanos y mendigos: Una aproximación a las experiencias sociales de trabajo y pobreza en la Buenos Aires de la primera mitad del siglo XIX".

Bila Sorj: São várias as autoras e livros que constituem o campo de estudos de gênero. Já temos obras clássicas como Beauvoir, Scott, Butler, Frazer, Haraway e tantas outras, que fazem parte do conjunto de textos básicos oferecidos nos cursos de gênero. Mais recentemente, autoras feministas negras como bell hooks, Angela Davis, Patricia Hill Collins e Kimberlé Crenshaw são cada vez mais referências indispensáveis nos estudos sobre interseccionalidades. Há também as autoras feministas decoloniais com suas críticas ao eurocentrismo e sua preocupação com o campo da epistemologia, com o modo como a sociologia conhece seus objetos de estudo. Há um crescimento considerável de autoras brasileiras que lidam com estas questões de maneira muito interessante, como pode ser aferido pela crescente publicação de livros e de revistas na área de gênero.

Bárbara Sutton: Habiendo estudiado sociología en los Estados Unidos, mi ingreso al conocimiento feminista es a través de esa área de estudio, que en mi caso luego se fue expandiendo hacia una mirada más interdisciplinaria en el contexto de mi desarrollo profesional. En ese sentido, para mi han sido influyentes los trabajos de Audre Lorde, Gloria Anzaldúa, Cherríe Moraga, Adrienne Rich, bell hooks, Chandra Talpade Mohanty, M. Jacqui Alexander, Judith Butler, Patricia Hill Collins y Angela Davis. También recuerdo el trabajo de Zillah Eisenstein, Anne Fausto Sterling, Raewyn Connell, Cynthia Enloe, Joan Acker, Marilyn Waring, Iris Marion Young, Vandana Shiva y María Mies, entre muchas otras. Durante mis primeros años de estudio en sociología, un libro de texto introductorio sobre temas de género que tuvo impacto en mí como estudiante fue Women's Lives: Multicultural Perspectives ("Las Vidas de las Mujeres: Perspectivas Multiculturales) de Gwyn Kirk y Margo Okazawa-Rey (1998). Ese libro 
hoy está en su séptima edición bajo el título Gendered Lives: Intersectional Perspectives (Vidas Generizadas: Perspectivas Interseccionales) (Kirk; Okazawa-Rey, 2020). No solamente los posicionamientos y explicaciones de las autoras, sino también la colección editada de escritos de teóricas, activistas y autoras diversas me presentaron temas y modos de analizar el mundo que hasta hoy me son útiles.

Catalina Trebisacce: Es muy difícil contestar porque hay una inmensa cantidad de trabajos que son recomendables. Pero creo que es especialmente importante incorporar lecturas del feminismo decolonial porque traen cuestionamientos a los supuestos y fundamentos más estructurales de la tradición teórica feminista que resultan muy productivos. En este sentido, una compilación de lectura obligada debería ser Tejiendo de otro modo: feminismo, epistemología y apuestas descoloniales en Abya Yala, compilado por Yuderkys Espinosa Miñoso, Diana Gómez Correal y Karina Ochoa Muñoz, del 2014. Por otra parte, y dando por supuesto ya las lecturas de Judith Butler y Paul Preciado, encuentro fundamental el estudio de una serie de trabajos que indagan epistemológicamente sobre el saber biomédico y su construcción sexual del mundo, como son los trabajos de Thomas Laqueur, Anne Fausto Sterling y Mauro Cabral, entre otrxs. En esta misma línea creo realizan aportes fenomenales los trabajos de Nicolás Cuello, Laura Contreras y la Cerda Punk que develan la gorfobia y el capacitismo que anida en el corazón del saber médico. Finalmente, creo que son muy importantes los recientes textos críticos de las tendencias punitivistas del movimiento feminista del último lustro. Recomiendo las lecturas de Tamar Pitch, Marta Lamas, Virginia Cano, Cecilia Varela, Deborah Daich, Ileana Arduino, Lucia Coppa, Agustina Iglesias Skulj, Marisa Tarantino, entre otros.

Cecília Maria Bacellar Sardenberg: Atualmente, a ampliação e complexidade dos estudos feministas de gênero tem sido tamanha que se torna muito difícil, senão impossível, destacar apenas um ou outro livro de preferência. Isso vai depender da área ou tema específico que trabalhamos em relação a essas temáticas.

Joana Maria Pedro: Eu tenho me dedicado ultimamente à discussão das perdas e ganhos das mulheres nos governos populistas de esquerda e de direita. Isso tem me levado a prestar atenção a algumas publicações. Destaco duas pessoas que já citei: Heloisa Buarque de Hollanda (2018) e Marlise Matos (2010). Além delas, Mary Beard (2018), com o livro Mulheres e poder: um manifesto, destinado ao público amplo e muito bem escrito. Entre as historiadoras, além do último livro que publiquei com Carla Bassanezi Pinsky (2012), Nova história das mulheres no Brasil, quero destacar trabalhos como Couro Imperial: raça, gênero e sexualidade no embate colonial (McClintock, 2010). Destaco, ainda, o livro 50 anos de femi- 
nismo: Argentina, Brasil e Chile, de Eva Blay e Lucia Avelar Melo (2016), e também o trabalho de Hildete Pereira e Débora Thomé (2018) Mulheres e poder: histórias, ideias e indicadores.

Mary Garcia Castro: As coletâneas que vem organizando Heloisa Buarque de Hollanda trazem trabalhos básicos tanto para mais conhecer contribuições do pensamento feminista latino-americano como do acervo internacional e temas em destaque por movimentos sociais feministas. A seguir, algumas referências que destaco: de Heloisa Buarque de Hollanda, Pensamento feminista hoje: perspectivas decoloniais (2020), Pensamento feminista brasileiro: formação e contexto (2019a), Explosão feminista: arte, cultura, política e universidade, de 2018, e Pensamento feminista: conceitos fundamentais (2019b). Ver aí as latino-americanas: Gloria Anzaldúa (2019), "La Conciencia de la Mestiza/Rumo a uma nova consciência"; Sueli Carneiro (2019), "Enegrecer o feminismo: a situação da mulher negra na América Latina a partir da perspectiva de gênero"; Lélia Gonzalez (2019), "A categoria político-cultural da amefricanidade", Maria Lugones (2019), "Rumo a um feminismo decolonial". 0 livro organizado por Marcia Esteves Calazans, Mary Garcia Castro e Emilia Piñeiro (2018), América Latina: corpos, trânsitos e resistências. De Margarita Aguinaga Barragán, Miriam Lang, Dunia Mokrani e Alejandra Santillana (2016), "Pensar a partir do feminismo: críticas e alternativas ao desenvolvimento", do livro Descolonizar o imaginário: debates sobre o pós-extrativismo e alternativas ao desenvolvimento. De Yuderkys Espinosa Miñoso, Diana Correal e Karina Ochoa Muñoz (2014), Tejiendo de otro modo: feminismo, epistemología y apuestas descoloniales en Abya Yala. De Rita Segato (2010), "Género y colonialidad: en busca de claves de lectura y de un vocabulario estratégico descolonial", publicado no livro La Cuestión Descolonial.

Nora Domínguez: Los libros de Rita Segato, de Alejandra Castillo en Chile. En mi país, que es el que más conozco; Verónica Gago, Virginia Cano, Malena Nijensohn y Catalina Trebisacce son jóvenes que están produciendo materiales muy valiosos.

Susana Rostagnol: ¡Bibliotecas enteras, no sabría por dónde empezar! Podría de manera general recomendar algunas revistas: Revista de Estudos Feministas, Pagu, Debates Feministas.

4. ¿Enseñas o has enseñado estudios de género? ¿Fue en el nivel de grado o posgrado? ¿Como materia optativa u obligatoria? ¿Qué recursos didácticos has utilizado? I Você ensina ou ensinou estudos de gênero? Na graduação ou na pós-graduação? Como disciplina optativa ou obrigatória? Quais recursos didáticos empregou?

Ana Peluffo: Enseño en una universidad norteamericana donde hay un departamento especializado de women's studies con el que estoy afiliada. Al mismo tiempo, trato de incor- 
porar el género en todos los seminarios o cursos de pregrado o grado que dicto en mi propio programa sobre cultura latinoamericana, visiones de infancia o políticas del afecto. No me gusta pensar el género de manera aislada, sino de forma interseccional, es decir yuxtaponiéndolo a discursos racializados de clase. También me parece importante pensar la construcción de feminidades o identidades queer en conjunción con las masculinidades o las infancias latinoamericanas. De la misma manera que las concepciones normativas de la femineidad excluyeron en el siglo XIX a las mujeres racialmente otras como sujetos de enunciación, también se excluyó de la visión hegemónica de la infancia a los niños de la calle o a los niños racialmente otros. En el último curso que dicté sobre feminismos y literaturas latinoamericanas incluí textos de diversas procedencias culturales como teoría feminista, cine, televisión y activismo político. Cuando leemos la carta de Sor Juana, por ejemplo, vemos la manera en que los feminismos del siglo XX-XXI se apropian de su figura. Hay una serie animada creada por las feministas mexicanas Marta Lamas y María Consuelo Mejía que traslada la figura de Sor Juana al presente, algo que también hacen diversas series, novelas y películas recientes. Cuando estudiamos temas relacionados con la violencia de género o la feminización y racialización de las políticas del cuidado en América Latina, vemos un episodio de la serie titulada Maltratadas para el primer caso y leemos cuentos de la escritora paraguaya-española Josefina Plá para el segundo. Otra película que me parece muy rica para trabajar el racismo andino desde una perspectiva feminista es La ciénaga, de Lucrecia Martel.

Andrea Andújar: Desde el año 2004, dicto materias y seminarios dentro de la carrera de Historia en universidades nacionales con programas que, o bien se articulan en torno a los estudios de género específicamente, o bien incorporan literatura procedente de este campo en la formulación de sus unidades. Esto lo he llevado a cabo tanto a nivel de grado como en posgrado. En el nivel de grado, las materias que dicté fueron optativas, en general vinculadas con historia de la historiografía. En cambio, dentro del posgrado, la mayoría de los seminarios que dicto tienen carácter obligatorio. Esto se debe a que forman parte de la cursada de Maestrías en Historia desarrolladas en universidades nacionales que requieren programas especializados en género, o bien dentro de doctorados en género, como el que tiene la Universidad de Buenos Aires o la Universidad Nacional de Córdoba, o en el marco también de especializaciones de posgrado brindadas por universidades nacionales. Los recursos didácticos que pongo en práctica combinan diversas estrategias. Las mismas comprenden desde la exposición y debate sobre ciertos estudios, hasta el análisis de fuentes de diversa factura (orales, escritas y dentro de ello, censos, cartas, volantes políticos, notas de periódicos etc.). En ocasiones, también recurro al uso de imágenes fotográficas, documentales y películas que sirven como disparadores para el debate y tratamiento de ciertos tópicos. 
Bila Sorj: Já ensinei disciplinas optativas na graduação e pós-graduação. Meu desafio hoje é reler e discutir a produção de mulheres que participaram dos círculos intelectuais responsáveis pela formação da disciplina [sociológica] na virada do século XIX ao XX. Autoras como Harriet Martineau, Charlotte Perkins Gilman, Pandita Ramabai, Olive Schreiner, Julia Copper, Marianne Weber e outras foram influentes em seu tempo, mas suas contribuições acabaram sendo ignoradas pelo cânone da disciplina. Essas autoras oferecem-nos um manancial de reflexões originais e sistemáticas sobre a origem e a natureza da modernidade emergente da sua época, vida privada, intimidade, casamento, sexualidade, divisão sexual do trabalho, vida cotidiana, temas que somente nos anos 1960 ganham relevo na sociologia. Revisitar essas autoras e estabelecer um diálogo crítico com o desenvolvimento da sociologia, permitirá expandir o cânone da disciplina, tal qual é transmitido nos livros textos e aplicado na docência.

Bárbara Sutton: Doy clases de estudios de género a nivel de grado y de posgrado (11 materias diferentes desde que comencé a trabajar en la Universidad de Albany en el 2006). Algunos de mis cursos son optativos (por ejemplo, Perspectivas Globales sobre las Mujeres) y otros son obligatorios (por ejemplo, Seminario de Investigación sobre Mujeres, Género y Sexualidad). Mi enfoque hacia la enseñanza está permeado no solo por el deseo de compartir conocimientos, sino también por el objetivo de inspirar y modelar formas de pensamiento crítico. Aspiro a que mis estudiantes puedan reflexionar sobre lo que aprenden y aplicar los conocimientos de manera concreta, relacionando los temas del curso con sus propias vidas y con el mundo social más amplio. Asimismo, ofrezco herramientas analíticas y prácticas para abordar cuestiones políticas de actualidad, tanto como integrantes de comunidades locales como de un mundo global. Me interesa no sólo transmitir saberes sino también que mis estudiantes puedan generar nuevos conocimientos en el contexto de mis cursos. Si bien mis clases incorporan materiales interdisciplinarios, tienen asimismo un fuerte énfasis sociológico, revelando conexiones entre lo que el sociólogo C. Wright Mills llamó problemas privados y asuntos públicos. Estos conceptos también resuenan de alguna manera con la noción feminista que "lo personal es político". Uno de mis objetivos pedagógicos es que mis estudiantes puedan entender la complejidad de las relaciones sociales, navegar sus contradicciones y comprender "a contracorriente". Me interesa entonces diversificar las miradas, escuchar aquellas voces marginadas, cuestionar normatividades y generar oportunidades para que quienes están en mi curso realicen su propio análisis y se comprometan con los temas que más les interpelan. Con estos fines, incorporo en mis clases películas, poesía, testimonios, ficción literaria, escritos teóricos, artículos y libros basados en investigaciones académicas y otras fuentes de conocimiento formal e informal. Si bien uso el tiempo de clase para explicar conceptos y trabajar con los textos asignados, 
también hay espacio para reflexionar sobre experiencias personales, explorar ideas a través de discusiones colectivas y aprender de activistas y docentes que a veces invito a mis clases. Procuro conectar con la comunidad y distintas unidades dentro de la universidad de modo que mis estudiantes puedan apreciar los vínculos entre lo que aprenden en clase y el mundo social más allá de la materia. Uno de mis desafíos ha sido integrar mi formación en las ciencias sociales con otros métodos de producción de conocimiento. El hecho de que mi "casa" académica sea el departamento de Estudios de Mujeres, Género y Sexualidad ayuda en ese sentido, dado el énfasis en la interdisciplinariedad. Estas iniciativas han abarcado desde visitas al museo de arte para comparar enfoques artísticos y científicos acerca de los archivos y modos de observación, hasta talleres con una artista que nos ayudó a abordar el estudio sociológico del cuerpo de un modo "encarnado", hasta proyectos de "artivismo" colectivo para el Día Internacional de las Mujeres.

Catalina Trebisacce: Enseño teoría de género y estudios queer en grado y en post grado, en universidades estatales y privadas. En el grado la materia tiene carácter optativo y en los cursos de posgrado son materias obligatorias porque se enmarcan en maestrías y doctorados específicos de estudios de género y teoría queer. Trabajo con material audiovisual y con fanzines y materiales de producción limitada y circulación acotada realizados por activistas y militantes.

Cecília Maria Bacellar Sardenberg: Já lecionei várias disciplinas dentro do campo dos estudos feministas, tanto em cursos de graduação quanto pós-graduação, valendo-me de diferentes recursos didáticos. Mesmo nos cursos e disciplinas não específicos, a perspectiva da antropologia feminista inseriu-se nas minhas atividades didáticas, uma vez que foi com base nessa perspectiva que fui construindo a minha aventura antropológica! É bom lembrar que nossa atividade docente não se encerra na sala de aula, tampouco no oferecimento de disciplinas. As atividades de orientação de alunas e alunos no desenvolvimento de trabalhos de conclusão e de pesquisas são parte crucial da docência, promovendo uma formação mútua, contínua, tanto do alunato quanto de professoras/es. Orgulho-me de ter tido a honra de orientar mais de 100 trabalhos de conclusão de cursos, seja monografias, dissertações de mestrado e teses de doutorado.

Dora Barrancos: A menudo desarrollo cursos de posgrado y los recursos didácticos que utilizo son muy clásicos: recurro a la oralidad, a la hermenéutica en el tratamiento de textos que considero claves. Cuando he desarrollado cursos de metodología de la investigación con perspectiva de género, lo conceptual resulta inescindible de los ejercicios prácticos.

Joana Maria Pedro: Sim, dei muitas aulas na graduação sobre gênero e até hoje dou aulas na pós-graduação — estou aposentada desde março de 2019, mas, continuo atuando 
na pós-graduação de História e no Doutorado Interdisciplinar em Ciências Humanas. Sempre foram disciplinas optativas na graduação. Atualmente os dois programas têm disciplinas obrigatórias, dentro da linha de pesquisa, nas quais a questão de gênero é a principal discussão. Usei filmes, aulas expositivas com slides em power point, seminários e discussão em sala de aula.

Mary Garcia Castro: Sim, na pós-graduação. Debates, participação ampliada das/dos participantes. Alguns títulos de cursos recentes que desenvolvi: Pós-colonialismo e De-colonialidades: Etnicidade, Reprodução, Gênero e Sexualidade - Vozes da África, com a colaboração de Thais Monticelli, no PPGSA/IFCS/UFRJ em 2019; Gênero e suas Relações com Geração, Etnia e Classe, em 2018 no UESB/PPG em Relações Étnicas e Contemporaneidade — Jequié (BA); Etnias, Gênero e Sexualidades, com Marcos Lopes de Souza, em 2018; Família, Gênero e Violência, com Vanessa Cavalcanti, na UCSAL/PPG, em Família na Contemporaneidade Salvador (BA), em 2016.

Nora Domínguez: Enseñé en el grado y en posgrado. Mis primeros cursos en el grado son de 1990 como materia optativa. Fui iniciadora de estos temas en la Carrera de Letras. Hoy el número de profesoras que dictan estos cursos ha crecido notablemente en cantidad y en apertura y diversidad de temas. Desde hace unos años incluyo estos temas, cada vez de manera más específica, en materias introductorias de carácter obligatorio, pero como temas de un programa. Utilizo textos teóricos sobre el concepto de género y la diferencia sexual y analizo textos literarios.

Susana Rostagnol: He dictado varios cursos que pueden enmarcarse en estudios de género a nivel de grado, como materias optativas; también he dictado materias en postgrado tanto obligatorias como optativas. En cuanto a los recursos utilizados, éstos han dependido fuertemente de las materias específicas; aunque de manera general puedo decir que siempre intento que aquello que es discutido a través de literatura específica, llegue a les estudiantes también en otros formatos, para ello me valgo de películas o fragmentos de película y noticias de prensa. La idea por detrás es que les estudiantes también se valgan de las emociones y la corporalidad para el proceso de aprendizaje.

5. ¿Cómo ves el futuro de los estudios de género? ¿Qué cuestiones temáticas, teóricas y metodológicas consideras fundamentales para el desarrollo del campo? / Como você vê o futuro dos estudos de gênero? Quais as questões temáticas, teóricas e metodológicas que você considera fundamentais para o desenvolvimento da área?

Ana Peluffo: Me parece que uno de los desafíos del feminismo contemporáneo es separar sus posturas sobre el género del capitalismo racializado. En este sentido, me parece 
que una de las ramas del feminismo más valiosas es la del feminismo del 99 por ciento que entronca con el movimiento de Occupy Wall Street en Estados Unidos y el movimiento de los indignados en España. Ese feminismo masivo se separa del feminismo neoliberal o corporativo que hace del individualismo y la autosuperación femenina uno de sus postulados más notorios. Creo que las violencias de género siempre se entrelazan con otros tipos de violencias fomentadas por el capitalismo global que son financieras, judiciales y gubernamentales. En los últimos años, el trabajo del colectivo Ni una menos consiguió ampliar el sujeto de enunciación del feminismo para incluir a mujeres lesbianas, trans y travestis y también a mujeres negras e indígenas. Aunque ha habido muchos avances a lo largo del tiempo, los retrocesos son igualmente preocupantes. Entre ellos, destaco las altas tasas de feminicidio en todo el continente que problematizan la visión utópica del feminismo, y la resistencia a legalizar el aborto. En este sentido me parece interesante destacar que, aunque en algunos países de América Latina se está haciendo un esfuerzo por visibilizar este tema, humanizar a las víctimas, realizar estadísticas, efectuar protestas masivas y crear ministerios de género, en Estados Unidos los datos son confusos y no existen estadísticas certeras a nivel federal. Hace algunos años los estudiantes no se interesaban en el feminismo porque pensaban que había igualdad de género y que vivíamos en sociedades post género o post feministas. Creo que la resurgencia del feminismo tiene que ver con la realización de que esa utopía igualitaria ha fracasado. Desde un punto de vista académico, uno de los desafíos teóricos es no pensar el patriarcado y el feminismo en términos binarios. Es decir, no caer en la tentación de celebrar todos los feminismos por igual sin problematizar o complejizar algunas de sus posturas. Hay feminismos racistas o esencialistas que se alimentan de una lógica neoliberal y que oprimen o marginan a mujeres explotadas por el capitalismo. También, creo que deberíamos prestar más atención a la manera en que las masculinidades van cambiando, o no, a medida que se extiende el feminismo.

Andrea Andújar: Creo que el futuro del campo de los estudios de género es tan prometedor como su presente, dada la densidad de las producciones con las que cuenta, los debates que alienta y enriquece (tanto dentro como fuera de las aulas), y de la riqueza de las teorías, conceptos y estrategias metodológicas que despliega. De todos modos, y justamente como lo denota la conformación de una agenda de problemas dinámica en su capacidad de renovación, quedan temas o tópicos pendientes de análisis o a ser examinados nuevamente a la luz de nuevos interrogantes. En el caso de la historia social del trabajo con perspectiva de género en la Argentina, restan variadas cuestiones, procesos y períodos para ser indagados con mayor detalle, explorando las maneras en que género, clase, etnicidad y marcas de color - dimensiones claves a mi juicio para comprender los procesos sociales - incidieron en la experiencia de la clase trabajadora y en la dinámica del conflicto de clases. Entre esas vacan- 
cias puedo mencionar el mundo del trabajo en la segunda mitad del siglo XX y en lo que va del actual; el mundo del trabajo rural, ámbito en el cual las mujeres quedan diluidas o encubiertas en el trabajo familiar; los vínculos entre mujeres trabajadoras y organizaciones feministas, así como los lazos con las izquierdas y derechas; la manera en que las sexualidades gravitan en el mundo del trabajo; la manera en que el género impacta en los procesos de proletarización pasados y actuales, con sus redefiniciones del sentido del trabajo y de su contenido. No pretendo con este listado agotar la agenda de tópicos y problemas históricos que merecen mayores estudios; pero sí denotar cuáles me resultan más atractivos en esos momentos.

Bila Sorj: Vejo que nos estudos de gênero a perspectiva interseccional tem progredido muito. Esta é uma das mais importantes renovações teórico-metodológicas dos estudos de gênero, ocorrida a partir dos anos 2000. Esse conceito foi cunhado nos Estados Unidos nos anos 1980, mas, também ali, só ganhou popularidade nas últimas décadas. 0 conceito de interseccionalidade oferece uma visão mais complexa sobre desigualdades sociais. Permite interpretar os efeitos sociais diferenciados quando categorias como gênero, classe e raça são postas em relação, ou seja, como raça e classe afetam as vivências de gênero e como o gênero incide sobre as experiências de classe ou de raça. Essa talvez seja uma boa ferramenta conceitual para entendermos, por exemplo, a questão que tem preocupado muitas ativistas feministas. Como interpretar que, após um ciclo de protestos de rua e ampla visibilidade feminista nas mídias sociais, terminamos em 2019 com um presidente eleito declaradamente misógino e racista? Ainda que seja relevante indicar que o voto feminino a favor de Bolsonaro tenha sido 10 pontos percentuais inferior ao masculino, não deixa de ser inquietante que metade das mulheres tenha votado nele. Precisamos novamente afiar o nosso olhar para compreendermos o imaginário social das mulheres na atualidade.

Bárbara Sutton: Creo que todavía queda mucho por hacer en un campo que, a pesar de continuar afianzándose en la academia, también ha sufrido embates — por ejemplo, a través de su descalificación desde los sectores de la derecha política, hostigamiento a docentes y académicas trabajando en temas específicos, o falta de recursos financieros suficientes para el desarrollo de programas de investigación. Desde el punto de vista académico, me parece que la interdisciplinariedad continúa siendo un desafío, especialmente en cuanto a lo metodológico. Al mismo tiempo, la integración de distintos saberes es esencial para poder comprender cabalmente muchos de los temas que competen a los estudios de género. Finalmente, creo que es vital que este campo de estudios no se desconecte de sus raíces activistas; que sin renunciar a los saberes teóricos académicos pueda hablar también en un lenguaje accesible; y que produzca conocimiento que importe para la creación de un mundo más justo. Ya sea interviniendo con una perspectiva feminista en la economía política, denunciando la sujeción 
de los cuerpos, desafiando el racismo y la colonialidad del poder, desarmando la matriz cis-heteronormativa, o imaginando otros mundos posibles (y estrategias para lograrlo), creo que los estudios de género tienen mucho para aportar.

Catalina Trebisacce: Entiendo que el crecimiento de los estudios de género es incontrolable. Como decía antes, se ha roto ya el aislamiento en el que existieron durante más de una década. Los aportes que traen los estudios de género reclaman revisar críticamente las epistemologías sobre las que se han construido tradicionalmente las distintas disciplinas de conocimiento científico. Por eso su aporte es tan fenomenal. La incorporación de los estudios de género no puede reducirse a una simple suma aditiva al conocimiento científico, sino que debe ser entendida como una transformación copernicana a los modos de construcción del saber científico moderno.

Cecília Maria Bacellar Sardenberg: Confesso que muito me preocupa o momento em que vivemos no país, com o avanço do fundamentalismo religioso em nossas esferas de poder. Há um processo de desmanche das universidades públicas, de desqualificação da ciência, de desvalorização de docentes - produtos do obscurantismo que paira sobre nossa sociedade e que representa uma grande ameaça à continuidade do ensino público, no geral, e dos estudos de gênero e feministas, em especial. Trata-se de um momento de retrocesso no tocante às conquistas no plano dos direitos humanos e sociais - de verdadeira ameaça à democracia —, como também de ameaça ao desenvolvimento da cultura e da ciência e tecnologia. Precisamos articular frentes de batalha para defendermos a continuidade de nossos estudos e defendermos a democracia em nosso país.

Dora Barrancos: Nuestros estudios sólo pueden ensancharse porque están acicateados por las movilizaciones, por la agencia por derechos, por el despertar de las subjetividades, por las luchas antipatriarcales. Tienen promisorio futuro mientras acompañen las insurgencias que plantea la desigualdad de géneros en nuestras sociedades.

Joana Maria Pedro: No momento, temos nos esforçado muito para impedir o retrocesso. Há muita resistência às discussões de gênero e, ao mesmo tempo, como já disse, muita curiosidade. Uma categoria como gênero não tem, necessariamente, vida longa. Outra palavra talvez possa vir a substituí-la. A categoria gênero, por vezes, tem sido associada ao academicismo, utilizada com uma linguagem pouco acessível. Penso que, talvez, se devesse torná-la mais compreensível. Afinal, é uma palavra guarda-chuva. Ou seja, com ela damos sentido a várias questões. No momento, ela ainda é muito útil. No futuro, não sei. Outras questões talvez tragam outras palavras.

Mary Castro Gomes: Apesar da ameaça conservadora e do ataque em especial às universidades e ao que chamam de ideologia de gênero, os estudos feministas e so- 
bre gênero já adquiriram legitimidade e uma dinâmica própria que só tende a mais se espraiar por diversas áreas. São muitos os temas básicos a pedir mais investimentos, e alguns não tão novos, mas que encontram desafios atuais, como por exemplo: 1. debates epistemológicos sobre colonialidade do poder, do saber e do ser, em especial os debates do feminismo decolonial; 2. teorias sobre a intersecção classe, raça, gênero e geração e a potencialidade de conceitos como Afrolatinidade (Gonzalez) e Quilombismo (Beatriz Nascimento), para estruturar novos conhecimentos em projetos de bem viver com corpos latino-americanos; 3. reprodução da vida, sexualidades e direitos reprodutivos, maternidade, maternagem, trabalho doméstico e nova divisão sexual e internacional do trabalho, considerando TICs e sociedade do conhecimento e o lugar do trabalho doméstico, remunerado e não remunerado e dos cuidados; 4. feminismo, materialismo e desigualdades sociais, como se nos apresenta no Manifesto Feminismo para os 99\% (Fraser; Arruzza, Bhattacharya, 2019); 5. feminismos e sexualidades, debates sobre movimento queer e sexualidades LFBTTQ+; 6. juventudes e feminismos, em movimentos sociais diversos. A diversidades de correntes feministas é, em si, uma das maiores contribuições da produção latino-americana e africana nestes tempos de barbárie.

Nora Domínguez: Creo haber respondido en las respuestas anteriores. Veo muy promisorio el desarrollo conceptual y temático porque ha habido una renovación generacional notable. Entiendo los estudios de género como estudios feministas y los de la diversidad sexual, esta apertura y articulación ha sido absolutamente promisoria y productiva para pensar conceptualizaciones diferentes y entender la incidencia de los cuerpos absolutamente atados a los modos de pensar y actuar.

Susana Rostagnol: Los estudios de género (feministas) son un campo interdisciplinario que debe profundizar su desarrollo en un doble diálogo: interdisciplinario, y al interior de las distintas disciplinas. Pienso que cualquier tema es pasible de ser abordado, siendo fundamental que sean temas cuyo estudio sea un aporte en el proceso emancipatorio de quienes ocupan los espacios subalternos, que visibilice las inequidades y las problematice. En cuanto a los aspectos teóricos, en este momento hay diversos desarrollos teóricos dentro del feminismo, considero que todos son necesarios, siendo fundamental tender puentes que permitan los diálogos teórico-políticos entre las distintas posturas. Respecto a las cuestiones metodológicas, pienso que es necesario profundizar en el camino propuesto por Donna Haraway, del conocimiento situado; a la vez que problematizar el papel de las emociones y del cuerpo en el proceso de producción de conocimiento. Todo esto, junto a una gran rigurosidad. 


\section{NOTA DE FIM}

1 Prefiro o termo estudos feministas a estudos de gênero, considerando, como adverte Saffioti (2004), a domesticação do conceito de gênero por agências internacionais e a minimização, em muitos usos, do gênero patriarcal e de sexualidades não heteronormativas.

\section{REFERÊNCIAS}

ANZALDÚA, Gloria. La Conciencia de la Mestiza/Rumo a uma nova consciência. In: HOLLANDA, Heloisa Buarque de (org.). Pensamento feminista: conceitos fundamentais. Rio de Janeiro: Bazar dos Tempos, 2019.

BARRAGÁN, Margarita Aguinaga et al. Pensar a partir do feminismo: críticas e alternativas ao desenvolvimento. In: DILGER, Gerhard; LANG, Miriam; PEREIRA FILHO, Jorge. Descolonizar o imaginário: debates sobre o pós-extrativismo e alternativas ao desenvolvimento. São Paulo: Fundação Rosa Luxemburgo, 2016.

BARRANCOS, Dora. La puñalada de Amelia (o cómo se extinguió la discriminación de las mujeres casadas del servicio telefónico en la Argentina. Trabajos y Comunicaciones, La Plata, v. 8, n. 34, p. 111-128, 2008.

BEARD, Mary. Mulheres e poder: um manifesto. São Paulo: Planeta do Brasil, 2018.

BLAY, Eva; MELO, Lucia Avelar (orgs.). 50 anos de feminismo: Argentina, Brasil e Chile. São Paulo: EDUSP, 2016.

CALAZANS, Marcia Esteves; CASTRO, Mary Garcia; PIÑEIRO, Emilia (orgs.). América Latina: corpos, trânsitos e resistências. Porto Alegre: Fi, 2018. 2 v.

CARNEIRO, Sueli. Enegrecer o feminismo: a situação da mulher negra na América Latina a partir da perspectiva de gênero. In: HOLLANDA, Heloisa Buarque de (org.). Pensamento feminista: conceitos fundamentais. Rio de Janeiro: Bazar dos Tempos, 2019.

CARUSO, Laura. Hombres a bordo: experiencia laboral y masculinidades en el mundo del trabajo marítimo en la primera posguerra. In: ANDÚJAR, Andrea et al. Vivir con lo justo: estudios de historia social del trabajo en perspectiva de género. Argentina, siglos XIX y XX. Rosario: Prohistoria Ediciones, 2016.

COSTA, Ana Alice Alcântara; SARDENBERG, Cecilia. Teoria e práxis feministas na academia. Os núcleos de estudos sobre a mulher nas universidades brasileiras. Estudos Feministas, Santa Catarina, núm. esp., p. 387400, 1994. https://doi.org/10.1590/\%25x

FARNSWORTH-ALVEAR, Ann. El misterioso caso de los hombres desaparecidos: género y clase en el Medellín de comienzos de la era industrial. Historia y Sociedad, n. 3, p. 141-167, 1996. http://dx.doi.org/10.15446/hys

FRASER, Nancy; ARRUZZA, Cinzia; BHATTACHARYA, Tithi. Feminismo para os 99\%: um manifesto. São Paulo: Boitempo, 2019.

GÉNERO BAJO ATAQUE. Direção: Jerónimo Centurión. Peru, Costa Rica, Brasil, Colômbia, 2018. (70 min.) Disponivel em: <https://www.youtube.com/watch?v=Aj3St_zUM7M>. Acesso em: 17 abr. 2020.

GONZALEZ, Lélia. A categoria político-cultural da amefricanidade. In: HOLLANDA, Heloisa Buarque de (org.). Pensamento feminista: conceitos fundamentais. Rio de Janeiro: Bazar dos Tempos, 2019.

HALL, Catherine. La historia de Samuel y Jemima: Género y Cultura de la clase trabajadora en la Inglaterra del Siglo XIX. Mora, n. 19, p. 83-100, 2013. https://doi.org/10.34096/mora.n19.458 
HOLLANDA, Heloisa Buarque de. Explosão feminista: arte, cultura, política e universidade. São Paulo: Companhia das Letras, 2018.

HOLLANDA, Heloisa Buarque de. Pensamento feminista brasileiro: formação e contexto. Rio de Janeiro: Bazar dos Tempos, 2019a.

HOLLANDA, Heloisa Buarque de. Pensamento feminista: conceitos fundamentais. Rio de Janeiro: Bazar dos Tempos, $2019 \mathrm{~b}$.

HOLLANDA, Heloisa Buarque de. Pensamento feminista hoje: perspectivas decoloniais. Rio de Janeiro: Bazar dos Tempos, 2020.

KIRK, Gwyn; OKAZAWA-REY, Margo. Gendered Lives: Intersectional Perspectives. New York: Oxford University Press, 2020.

KIRK, Gwyn; OKAZAWA-REY, Margo. Women's Lives: Multicultural Perspectives. Mountain View, CA: Mayfield, 1998.

LOBATO, Mirta Zaida. La vida en las fábricas: trabajo, protesta y política en una comunidad obrera (19041970). Buenos Aires: Prometeo, 2001.

LUGONES, Maria. Rumo a um feminismo decolonial. In: HOLLANDA, Heloisa Buarque de. Pensamento feminista: conceitos fundamentais. Rio de Janeiro: Bazar dos Tempos, 2019.

MATOS, Marlise. Movimento e teoria feminista: é possivel reconstruir a teoria feminista a partir do Sul Global? Revista de Sociologia e Política, Curitiba, v. 18, n. 36, p. 67-92, jun. 2010. https://doi.org/10.1590/S010444782010000200006

MCCLINTOCK, Anne. Couro Imperial: raça, gênero e sexualidade no embate colonial. Tradução: Plinio Dentzien. Campinas: Editora da Unicamp, 2010.

MIÑOSO, Yuderkys Espinosa; CORREAL, Diana Gómez; MUÑOZ, Karina Uchoa (orgs.). Tejiendo de otro modo: feminismo, epistemología y apuestas descoloniales en Abya Yala. Popayán: Editorial Universidad del Cauca, 2014.

MITIDIERI, Gabriela; PITA, Valeria Silvina. Trabajadoras, artesanos y mendigos: una aproximación a las experiencias sociales de trabajo y pobreza en la Buenos Aires de la primera mitad del Siglo XIX. Anuario del Instituto de Historia Argentina, v. 19, n. 1, 2019. https://doi.org/10.24215/2314257Xe083

PALERMO, Silvana. ¿Trabajo masculino y protesta femenina? La participación de las mujeres en la gran huelga ferroviaria de 1917. In: BRAVO, M. C.; GIL LOZANO, F.; PITA, V. (orgs.). Historia de luchas, resistencias y representaciones. Mujeres en la Argentina, Siglos XIX y XX. Tucumán: EDUNT, 2007.

PELUFFO, Ana. En clave emocional. Cultura y afecto em América Latina. Buenos Aires: Prometeo, 2016.

PEREIRA, Hildete; THOMÉ, Débora. Mulheres e poder: histórias, ideias e indicadores. Rio de Janeiro: FGV Editora, 2018.

PINSKY, Carla Bassanezi; PEDRO, Joana Maria. Nova história das mulheres no Brasil. São Paulo: Contexto, 2012.

RIBEIRO, Djamila. O que é lugar de fala? Belo Horizonte: Justificando, 2017. 
RIBEIRO, Djamila. Quem tem medo do feminismo negro? São Paulo: Companhia das Letras, 2018.

SAFFIOTI, Heleieth I. B. Gênero, patriarcado, violência. São Paulo: Editora Fundação Perseu Abramo, 2004.

SARDENBERG, Cecilia ; COSTA, Ana Alice Alcântara. "Teoria e práxis feministas na academia. Os núcleos de estudos sobre a mulher nas universidades brasileiras" Estudos Feministas, Santa Catarina, 1994, pp. 387-400.

SARDENBERG, Cecília. Mães e filhas. Etapas do ciclo da vida, trabalho e família entre o antigo operariado baiano. Caderno CRH, Salvador, v. 11, n. 29, p. 21-47, 1998. http://dx.doi.org/10.9771/ccrh.v11i29.18692

SCHETTINI, Cristiana. Viajando solas: prácticas de vigilancia policial y experiencias de prostitución en América del Sur. In: TRUJILLO BRETÓN, J. A. (org.). En la encrucijada: historia, marginalidad y delito en América Latina y los Estados Unidos de Norteamérica (siglos XIX y XX). México: Universidad de Guadalajara Ediciones, 2010.

SEGATO, Rita Laura. Género y colonialidad: en busca de claves de lectura y de un vocabulario estratégico descolonial. In: QUIJANO, Aníbal; NAVARRETE, Julio Mejía (orgs.). La Cuestión Descolonial. Lima: Universidad Ricardo Palma, Cátedra América Latina y la Colonialidad del Poder, 2010.

THOMPSON, Dorothy. Las mujeres y la radicalidad política en el siglo XIX: una dimensión ignorada. Mora, n. 19, p. 65-82, 2013. https://doi.org/10.34096/mora.n19.457

VASSALLO, Alejandra. Sin Dios y sin jefe. Políticas de género en la revolución social a fines del Siglo XIX. In: BRAVO, M. C.; GIL LOZANO, F.; PITA, V. (orgs.). Historia de luchas, resistencias y representaciones: mujeres en la Argentina, siglos XIX y XX. Tucumán: EDUNT, 2007.

ZEMON DAVIS, Natalie. El regreso de Martín Guerre. Madrid: Akal, 2013.

ZEMON DAVIS, Natalie. Mujeres en los márgenes: tres vidas del siglo XVII. Madrid: Cátedra, 2004. 